\title{
The Unintended Consequences of the Rat Race: The Detrimental Effects of Performance Pay on Health
}

\author{
by \\ Keith A. Bender* and Ioannis Theodossiou $\dagger$
}

* Professor, Department of Economics and Centre for European Labour Market Research, University of Aberdeen, Edward Wright Building, Dunbar Street, Aberdeen, AB24 3QY, SCOTLAND, UK; email: kabender@abdn.ac.uk

† Professor, Department of Economics and Centre for European Labour Market Research, University of Aberdeen, Edward Wright Building, Dunbar Street, Aberdeen, AB24 3QY, SCOTLAND, UK; email: theod@abdn.ac.uk

Forthcoming, Oxford Economic Papers. 
The Unintended Consequences of the Rat Race: The Detrimental Effects of Performance Pay on Health

\begin{abstract}
Although performance pay schemes have been linked to labour market productivity, one unintended consequence, suggested as early as Adam Smith, is that performance pay is detrimental to health. Recent research has shown that there is a positive relationship between performance pay and injuries on the job. This paper focuses on the consequences of performance pay on health and investigates if there is a link between performance pay and selfreported general health or specific illnesses. Using data from the British Household Panel Survey, this study utilizes survival analysis to show that being in jobs with a performance pay element increases the likelihood of health deterioration, ceteris paribus.
\end{abstract}

Keywords: Performance Pay, health, duration models

JEL: J33, I1 


\section{The Unintended Consequences of the Rat Race: The Detrimental Effects of Performance Pay on Health}

\section{Introduction}

The economics literature suggests that there is a link between performance pay and increased productivity. Thus research reveals that pay based on the performance of workers (usually in the form of piece rates, merit pay or similar pay-for-performance schemes) generate higher productivity through an increased incentive for effort or by offering incentives for more highly productive workers to sort themselves into these types of jobs (Lazear, 2000).

However, a related literature examines the unintended consequences of such payment schemes. If the contract is not set up appropriately, 'adverse specialization’ (MacDonald and Marx, 2001) can occur where workers perform only those aspects that are rewarded, while ignoring other aspects that are not. Thus, workers may stress quantity over quality or overuse physical capital in order to increase production. These unintended consequences of performance pay schemes have led some researchers to question whether these schemes actually increase profitability, despite the fact that they may increase worker productivity.

An interesting and little explored potential unintended consequence of performance pay is its effect on health. Adam Smith first observes in The Wealth of Nations, "Workmen ... when they are liberally paid by the piece, are very apt to overwork themselves and to ruin their health and constitution in a few years” (Smith, 1776, p. 83). Except for a limited number of studies (e.g. Foster and Rosenweig, 1994, and Bender et al., 2012), this observation has not been empirically tested, and the small literature that has examined this topic has focused very narrowly on injuries 
at work. In line with the original idea of Smith, the aim of this paper is to use a nationally representative dataset to examine the effects of performance pay on other health outcomes, particularly ones affected by stress. Thus, the study investigates whether increases in the length of time paid using performance pay negatively impact the 'health and constitution in a few years'.

The following section briefly reviews the literature on the unintended consequences of performance pay and the small set of papers that link health to performance pay. Section III discusses the potential pathways that performance pay might impact health over time. Section IV reviews the data and methodology. Section V reports the results, while Section VI empirically examines potential pathways for the effect of performance pay on health. A final section concludes the paper.

\section{Brief Literature Review.}

It is intuitive to think that certain job characteristics are correlated with health. For example, Case and Deaton (2005) use cross sectional data to show that manual workers have worse health than non manual workers, even after controlling for factors such as education and income. More recently, Fletcher et al. (2011) find that long exposure to adverse physical demands and environmental conditions in their occupations cause workers to have worse health. However, most papers in this vein do not examine the effect of particular job characteristics.

The literature that links health and performance pay is small and is often focused on case studies of particular industries or occupations. Sundstroem-Frisk (1984) finds that accident rates among 
Swedish loggers is lower for those paid hourly rates rather than piece rates. Saha et al. (2004) investigate fertilizer production workers in India to show those on performance pay experienced higher workplace accidents. Freeman and Kleiner (2005) report evidence from a US shoe manufacturer that piece rates are associated with higher workers compensation costs. Toupin et al. (2007) report higher heart rates for Canadian loggers paid by piece rates, suggesting 'negative consequences for worker health and safety.' Several papers on over-the-road truckers in the US (Williamson et al. 2009, Rodriquez et al. 2006, Belman et al. 2005, and Monaco and Williams 2000) generally find that truckers paid by the hour have smaller probabilities of being in accidents compared to truckers who get paid by the mile.

Three papers are more closely aligned with this paper's focus. The first is by Foster and Rosenweig (1994). Like the papers referenced above they, focus on a narrow occupation (subsistence farmers in the Philippines) but they link performance pay with overall health, as opposed to injuries on the job. They approximate overall health by the body mass index (BMI) which is shown to be lower for farm workers paid piece rates, ceteris paribus. Since these subsistence farmers have very low BMIs to begin, low BMI indicates worse health since.

The other two papers are by Bender et al. (2012) and Artz and Heywood (2013). Both focus on the link between performance pay and workplace injury. Unlike the papers discussed above, they consider the performance pay-injury relationship across many different occupations and industries. Bender et al. (2012) use a Europe-wide cross-sectional dataset (the European Working Conditions Survey) to find a strongly robust relationship between workers with piece rates experience and higher probabilities of workplace injury, ceteris paribus. Artz and 
Heywood (2013) employ the US National Longitudinal Survey of Youth to find that this relationship exists even when controlling for individual and individual-employer fixed effects.

The goal of the current paper is to extend these last papers by examining the relationship between performance pay experience and broad measures of health, using a nationally representative dataset that covers many different occupations and industries. The difficulty with this approach is identifying a dataset that includes measures of performance pay and health and contains a wide array of microeconomic information (e.g. socio-economic data, education, earnings, etc). Standard microeconomic datasets in the US such as the Current Population Survey, the Panel Study on Income Dynamics, and even the National Longitudinal Survey of Youth do not generally contain all the necessary variables. (Indeed, this may explain, in part, the lack of research in the area.) However, these data do exist for a subset of years in the British Household Panel Survey (BHPS) and, thus, it is this data source that provides the data for this study. ${ }^{1}$

\section{Potential Pathways}

The literature above only alludes to potential pathways that might generate worse health due to performance pay. Bender et al. (2012) suggest that one pathway for workplace injury is the increased effort caused by performance pay giving incentives to increase their speed on the job

\footnotetext{
${ }^{1}$ One dataset that does have these measures is the US Health and Retirement Study (HRS), but it has the unsatisfactory aspect of including very limited age range of 51 to 61 year olds in 1992. Thus, it is more appropriate to use a survey such as the BHPS which includes workers of all ages.
} 
or take greater risks on the job. This point is echoed in several of the papers mentioned above that focus on particular occupations.

While the above might explain the link between performance pay and injuries on the job, other pathways are possible when the cumulative effects of performance pay on health are considered. One way is through increased stress associated with performance related pay. This stress might be generated in a variety of ways. Although not a focus of their study, Dohmen and Falk (2011, Table 5) analyse data from a series of experiments to find that piece rate payments generated both more effort and more stress and exhaustion than those paid a fixed rate, particularly after participants were allowed to sort into a payment scheme. Medical evidence, such as the reviews by Cooper and Marshall (1976) and Blake et al. (1996) shows that this physical stress can lead to adverse health outcomes, both physiological (e.g. skin problems, hypertension and fatigue) and psychological (e.g. depressions, emotional fatigue and feelings of anxiousness). Furthermore, performance related pay is generally found to be more variable than salaried or time based pay. This variability may induce further stress with the increased uncertainty of an income stream. ${ }^{2}$

Another potential pathway is an implication of the view that health status is determined through a health production function. This function could have many arguments, but one key aspect to better health is time - time spent in healthy behaviours such as exercise, learning about nutrition

\footnotetext{
${ }^{2}$ Of course, this would be mitigated by any compensating wage differential paid for performance related pay. Furthermore, there is some evidence from recent papers such as Grund and Sliwka (2010) and Cornelissen et al. (2011) that less risk averse workers sort into jobs that pay for performance. However, as shown below and in Artz and Heywood (2013), the inclusion of proxy measures of risk tolerance does not affect the health-performance pay relationship.
} 
and good health, relaxation from the stress of work, cooking healthy meals etc. Thus, health production is a form of household production. If, as Lazear and others have shown, performance pay generates increased effort, this would imply more hours at work because the opportunity cost of time in healthy behaviour increases. Therefore, there will be fewer hours available to put into the health production function (e.g. Mullahy and Robert, 2010). This generates worse health. However, the effects may not be instantaneous (as they may be if a worker takes a greater risk in the job and an injury immediately results). One would expect that the effects may build up over time as, for example, workers spend less time in exercise and gradually gain weight which, in turn, results to adverse health conditions such as heart disease.

\section{Methodology and Data}

There are several potential pathways that point to performance pay leading to adverse health outcomes but, one commonality is that any ill health from performance pay is not expected to be instantaneous. Hence, one may expect that long exposure to performance pay would manifest itself on health over a period of time. This indicates the need for a panel dataset rather than a cross sectional one, since one would want to observe the effect of performance pay on health over a period of time. Thus, the focus of this study is to evaluate the impact of performance pay on the duration of good health spells using duration/hazard models. Specifically, this study examines whether performance pay increases the hazard of falling out of good health. ${ }^{3}$

\footnotetext{
${ }^{3}$ This approach fits into a newer line of research that is examining such issues as the effect of unemployment on the duration of good health as in Cooper et al. (2008).
} 
In the dataset, each individual is observed at a number of points in time. The time intervals are of one year of length, and so the interval boundaries are $t=1,2,3, \ldots$ and the interval $t$ is $(t-1, t]$. Thus, the dependent variable is the dummy variable indicating that at interval $t$, the individual remained in good health. Otherwise, the spell of good health has been observed to end. A spell of good health can either be complete $\left(c_{i}=1\right)$ or right censored, i.e. either the individual continues to be in good health at the end point or the individual left the sample before the end point $\left(c_{i}=1\right)$. In this specification, re-entry into the panel is not allowed (since this would introduce problems of endogeneity), and so only a single completed or uncompleted spell for each individual is included.

The results from estimating Cox (1972) hazard models are first presented. Although this methodology is frequently used in the literature, a number of potential problems are associated with it in the context of this study. First, it assumes a continuous hazard. However, given that the data used here are yearly for only 10 years, a discrete hazard model might be more appropriate. Second, there may be a series of unobservable characteristics that are specific to the worker and can affect the hazard. This uncontrolled individual heterogeneity is called 'frailty' in the literature and can bias the estimated coefficients in the hazard regressions (see also Heckman and Borjas 1990 and Lancaster 1979). Jenkins (2013, Chapter 8, p. 81) stresses the importance of correcting for frailty to control for "omitted variables (unobserved in the available data, or intrinsically unobservable such as 'ability')". Thus, this study employs the Jenkins (1995, 2004). approach to estimating the effect of performance pay after controlling for both observable

\footnotetext{
${ }^{4}$ According to Jenkins, this methodology is an adaptation of a frailty correcting methodology proposed by Prentice and Gloeckler (1978) and modified by Meyer (1990). This study follows the methodology as it is set out in Jenkins
} 
and unobservable individual characteristics on the length of time an individual remains in good health. It is important to note that this methodology controls for unobserved factors either from the employee side (e.g. the individual's attitude to risk) or by the employer side (e.g. employment relations). Specifically it is assumed that the instantaneous hazard rate function for person $\mathrm{i}$ at time $\mathrm{t}>0$ is assumed to take the proportional hazard form:

$\lambda_{i t}=\lambda_{0}(\mathrm{t}) \varepsilon_{i} \exp \left(X_{i t}{ }^{\prime} \boldsymbol{\beta}\right)=\lambda_{0}(\mathrm{t})\left[\exp \left(X_{i t}{ }^{\prime} \boldsymbol{\beta}\right)+\log \left(\varepsilon_{i}\right)\right]$

where $\varepsilon_{i}$ is a Gamma distributed random variable with mean 1 and variance $\sigma^{2}=v$. Thus, the model incorporates a Gamma distributed random variable to take into account the frailty or unobserved (or omitted variable) heterogeneity between individuals, that is to control for factors and characteristics that are not observed by the researcher in the dataset but they affect the duration of the good health spell.

The discrete - time hazard function for the model is

$h_{t}\left(X_{i t}\right)=1-\exp \left\{-\exp \left[X_{i t}{ }^{\prime} \boldsymbol{\beta}+\gamma_{t}+\log \left(\varepsilon_{i}\right)\right]\right\}$.

The log-likelihood of eq. (2) is

$\log L=\sum_{i=1}^{N} \log \left\{\left(1-\mathrm{c}_{i}\right) \mathrm{A}_{i}+\mathrm{c}_{i} \mathrm{~B}_{i}\right\}$

where

$\mathrm{A}_{i}=\left(1+v \sum_{j=1}^{t_{i}} \exp \left[X_{i j}^{\prime} \beta+\theta(j)\right]\right)^{-1 / v}$

and

(1995) by using the "pgmhaz8” subroutine available in STATA (Jenkins, 2004). Note that there is a second similar methodology (Jenkins, 2005)) that uses discrete mixture distribution to summarize unobserved individual heterogeneity (hshaz) outlined in Cooper et al. (2008). Using this methodology, the qualitative results are very similar to the reported results below and are available upon request. 
$\mathrm{B}_{i}=\left(1+v \sum_{j=1}^{t_{i}} \exp \left[X_{i j}^{\prime} \beta+\theta(j)\right]\right)^{-1 / v}-\mathrm{A}_{i}$, if $t_{i}>1$

or

$\mathrm{B}_{i}=1-\mathrm{A}_{i}$, if $t_{i}=1$

and $\theta(j)$ is a function describing duration dependence in the hazard rate (see Jenkins, 1995, for further details).

Finally, the methodology adopted in this paper establishes the direction of causality and circumvents the problem of endogeneity. In particular, the sample consists of individuals who have reported good health at the initial period (the start of the survey). When the individual exits good health, his or her time in good health is recorded and this event should be expected to be an outcome of events occurring during the intervening period. Thus, this procedure ensures that the direction of causality is from performance pay to health. In addition to this, unobserved heterogeneity is controlled for in the Jenkins (2004) methodology. As a further robustness check, indicators of past bad health are included to explicitly control for the initial conditions of poor health.

Nevertheless, one could argue that even without controlling for endogeneity, the expected endogeneity bias should move the coefficient towards zero. This is because if there is sorting; healthier individuals would be more likely to reap higher rewards from performance pay, which works in the opposite way of the arguments above. Thus, even if one does not control for endogeneity using the methods above, the estimates will be lower bounds of the effect of performance pay on health. 
The data utilized in this study are from the British Household Panel Survey (BHPS). The key question which is used for the main independent variable is introduced in the survey in wave eight. The question is, 'Does your pay include performance related pay?' Thus, there are ten waves which provide this information on performance pay for workers in wage and salary jobs (self-employed are excluded), since the dataset goes up to Wave $19 .{ }^{5}$ Because the issue at hand is to assess whether long exposure to performance pay generates worse health, the proportion of time (over the observation period) spent in performance pay is utilised. ${ }^{6}$

This study utilises four measures of health. The first is a measure of subjective overall health and is derived from the question, 'Please think back over the last 12 months about how your health has been. Compared to people of your own age, would you say that your health has on the whole been excellent, good, fair, poor or very poor?' In order to specify the duration of good health, the following methodology is used: Individuals who report in wave eight that they are in

\footnotetext{
${ }^{5}$ There is a question asked every wave about whether pay has any bonus payment in it. Estimations using this variable generated no statistically significant results, although 'bonuses' is too broad a term for the purposes of this study since they may or may not be based on personal performance and thus may not generate the kinds of behaviour which might decrease health. Indeed this is potentially an issue for the question from which performance pay is identified, since it could be considered broadly to include group-based performance. One might argue that the negative health effects would be less pronounced with such group-based forms of compensation which might bias the results to finding no effect. That a consistent relationship is found indicates that this effect is relatively small compared to the effect of individually-based performance pay.

${ }^{6}$ A number of variations on this key variable are also used including a dummy variable for whether the respondent was in performance pay in the last period of observation or dummy variables of splines of the proportion of time spent in performance pay. Results using these variations are qualitatively similar to those below and are available upon request.
} 
excellent or good health (and are employed in a wage and salary job in order to identify performance related pay) are selected. The periods that workers who remain in this status are counted until workers either drop out of the survey while still in good health (perhaps because of non response or because of a loss of employment), continue in good health in all waves, or report fair, poor, or very poor health. The first two groups are 'censored' observations.

Three measures of physical health are also analysed - whether workers suffer from heart problems, stomach/digestive problems, or anxiety/depression - which are all closely aligned with adverse health reactions to stress. As with subjective health, each sample starts with individuals who report in wave eight that they are not suffering from the respective illness. Then periods of good health are counted until workers either drop out of the survey in good health or report the onset of the health problem.

The regressions also control for standard demographic and health variables, including gender, education, age, current smoking status, four categories of earned income, marital status, the log of hours worked, broad industry and occupational indicators, and region of residence, all of which are measured at the time of the last observance of the respondent.

\section{Results.}

\section{A. Survival Plots}

Figure 1 shows Kaplan-Meier survival plots for the subjective health measure by whether the respondent has been in performance pay less or more than 50 percent of the observation time. 
The graph clearly shows there to be a greater hazard of falling into poor health for those in performance pay at least 50 percent of the time.

One complicating factor to these patterns might be income. Despite the fact that the UK has universal health care through the National Health Service, it is still likely that those who have higher income may enjoy superior health compared to lower income people. Since performance pay will likely generate higher income, there could be a confounding influence of increased income helping keep good health survival rates higher for those paid by performance. In Figure 2, the sample is disaggregated by whether a worker's earned income is above the median ('highincome'=1) or below the median ('highincome'=0). The highest hazard is for the group of workers who have been in performance pay more than 50 percent of the time and have income below the median. However, the negative effect of performance pay is offset somewhat by increased income as shown in the hazard for workers with 50 percent of time in performance pay and income above the median - a similar hazard to those with low income, but low exposure to performance pay. The lowest hazard is for the high income and low performance pay group.

Finally, Figure 3 shows the survival plots for the three objective health measures. As with the subjective measures, those who are in performance pay for more than 50 percent of the time have lower survival probabilities, particularly if their earned income is below the median. ${ }^{7}$

\section{B. Regression Results.}

\footnotetext{
${ }^{7}$ Formal tests for equality of the survivor functions generally failed for all figures, particularly among the relatively low earnings group. Results are available from the authors.
} 
In addition to income there could be a variety of confounding factors driving these results. Hence, controlling for worker heterogeneity is important. For the subjective health measure, the hazard ratios for the percentage of time spent in performance pay are reported in Table 1 for different econometric specifications and samples. ${ }^{8}$ The first column reports hazard rates from Cox proportional hazard regression results. For the overall sample, increases in the percentage of time spent in performance pay are associated with higher odds of falling into worse health. Although the point estimate is statistically significant at the 1 percent level, it seems that the marginal impact is quite small (an increase in odds by 1.004), but this is only for a one percentage point rise in the percent of time for performance pay. A one standard deviation rise in percent of time (about 25 percentage points) would generate much higher odds of poor health, with the projected hazard at 1.103. The next column reports the odds ratio on performance pay using the Prentice-Gloeckler (1978) method that controls for discreteness in the hazard functions. As can be seen, controlling for this discreteness generates little difference in the odds ratio, increasing it from 1.004 to 1.005 , while maintaining its statistical significance.

The above regressions circumvent the problem of endogeneity. The control for endogeneity comes through the set up of the sample, where the sample consists of individuals who have reported good health at the initial period (here in Wave 8 of the BHPS). When the individual exits good health, his or her time in good health is recorded, and this event should be expected to be an outcome of events occurring during the intervening period. Thus, this procedure ensures

\footnotetext{
${ }^{8}$ Full results for the overall sample for subjective health for the three econometric specifications are given in Appendix Table A1. Generally the hazard ratios for the independent variables correspond to intuition and previous findings. Full results for all regressions are available from the authors.
} 
that the direction of causality is from performance pay to health circumventing the problem of endogeneity. Nevertheless, as a robustness test a series of dummy variables of the number of times the worker had reported bad health in the first eight waves of the survey are included as a measure of the state of worker's previous health. As can be seen, this has no appreciable effect on the point estimate or statistical significance.

The control for unobserved heterogeneity or frailty comes through the use of the PrenticeGloeckler (PG) (1978) methodology. Interestingly this generally increases the hazard ratio. So while the impact of a one percentage point increase in the amount of time spent in performance pay increased the odds by 1.005 times without controlling for frailty, the odds jump to 1.013 when frailty is controlled for (or a projected hazard of 1.396 for a one standard deviation rise in the percent of time in performance pay). The jump is even almost as big when previous health is controlled (1.004 to 1.009). However, the pattern of performance pay correlating with worse health outcomes remains regardless of controlling for these frailty effects. ${ }^{9}$

Further, Table 1 contains the results of the subjective health measure for different samples. There is little difference by gender for the Cox or PG without frailty regressions, and the odds are generally higher when frailty is controlled for all samples, although the point estimate is statistically insignificant for the female sample in the frailty corrected regressions. Unlike in the

\footnotetext{
${ }^{9}$ However as mentioned above, even if the endogeneity is not completely circumvented, the direction of the bias is almost certainly towards a positive relationship between performance pay and health, since those who are generally more healthy will naturally be more likely to want to be paid by performance. Thus, if one finds consistently negative and statistically significant relationships, in the presence of endogeneity, this implies that the regressions are underestimating the negative effect of performance pay on health.
} 
figures, it does not seem to matter much if one is above or below median income (after controlling for the other covariates including income) as the hazards are nearly identical regardless of the estimation method. Finally, workers in manual occupations generally have higher hazard ratios than workers in nonmanual occupations, ceteris paribus.

Table 2 contains the hazard ratios for the percentage of time in performance pay for the three objective health measures by regression method and sample. Generally, the results show that increased time in performance pay, ceteris paribus, leads to a higher hazard of poor health, typically in the 1.005 to 1.010 range for the Cox regression and from 1.008 to 1.049 for the PG regressions with frailty corrections. Most, although not all, are statistically significant at least at the 10 percent level (only ten of 72 coefficients are not statistically significant). Although one cannot directly test the difference in the hazard ratios across health groups, it seems that women have slightly higher hazards for both heart health and anxiety/depression where males have higher hazards for stomach health. There are no consistent differences by income level for heart health or anxiety/depression, although higher income workers have higher hazards for stomach health. Non manual workers are more susceptible to heart problems, while manual workers are more likely to have stomach and anxiety/depression problems. Controls for heterogeneity (either by including past health or frailty controls) do not seem to affect the pattern of results in any appreciable manner.

\section{Robustness Checks}

A series of other regressions are utilised to investigate how robust these results are. First, even though the study controls for unobserved heterogeneity and endogeneity, there is still the 
possibility of not adequately controlling for the level of risk via the workers attitude to risk. One may argue that attitude to risk may affect health (e.g. Kowert and Hermann 1997; Nicholson et al. 2005; Khwaja et al. 2006; Lia and Liu 2008) and that risk averse workers may not opt for performance pay. Although already in the regressions there are controls for some factors that are correlated with risk such as smoking behaviour (Viscusi 2001) and industry and occupation, there is no direct measure of risk attitude included in the regressors. The BHPS does not include questions that provide appropriate measures of attitude to risk. However, two variables are used to approximate attitude to take risk (a) have reported gambling winnings (b) if the individual can be characterized as an introvert. ${ }^{10}$ The inclusion of either sets of controls do not affect the results appreciably.

Second, one might be concerned about the samples used in the study. Two issues are investigated. First, given that there is only a limited panel there may be an unavoidable discreteness in the percentage of time spent in performance pay. Thus, models where individuals are observe for at least 4 waves are estimated. As above, the results do not change appreciably. Finally, a series of regressions based on a sample of only those with some performance pay that is on the selected group- are estimated. The point estimates tend to be slightly higher than those reported in Tables 1 and 2, but all are statistically significant and indicate that the longer one stays in performance pay, the higher the odds to drop into poor health ${ }^{11}$.

\footnotetext{
${ }^{10}$ This comes from a question in the BHPS that asks whether a person thinks that 'Life is full of opportunities.' People who answer 'No' to this are labeled as an introvert.

11 These results are available from the authors on request.
} 


\section{Pathways}

Overall, there seems to be consistent evidence that increases in the percentage of time in performance pay generates a higher hazard of falling out of good health, ceteris paribus. However, as discussed above, it is interesting to explore what pathways might be generating this effect. One potential source might be on the amount of time available for 'healthy' activities. If performance pay increases time spent at work, there will be fewer hours in the day, potentially, to engage in healthy behaviours. Taking the sample of healthy workers from Wave 8 of the BHPS (the starting sample from above) and running a regression of total weekly hours (both regular and overtime hours) on performance pay and a series of other demographic and job characteristics $^{12}$, it is found that the coefficient on performance pay is 1.29 and is significant at the ten percent level, meaning that workers on performance pay work almost 1.3 hours more than those not in performance pay. If a sample of all workers is used, regardless of their health, the marginal effect is 1.5 hours, which is statistically significant at the one percent level.

Unfortunately, the BHPS does not have a large array of information on the leisure activities of respondents. Nevertheless, for Wave 8 there is information on the amount of time participating in sports, participating in evening classes (including 'keep fit' light exercise classes), drinking, and eating out. These are all five point ordered responses from 'Never/almost never' to 'at least once a week'. Table 3 has selected results from ordered probit estimations using Wave 8 data, both with the 'Healthy Worker' sample used in the duration analysis above, but also for 'All Workers' in Wave 8, regardless of health. Interestingly, there seems to be little effect on some leisure

\footnotetext{
${ }^{12}$ Other controls include gender, education, age, age squared, marital status, currently smoking, labour income, occupation and region. Regressions that include total numbers of hours, give similar results.
} 
activities like participating in sports or in evening classes. However, there is an increase in participation in both frequent drinking and for eating out. While these are not necessarily unhealthy behaviours, dietary guidelines on both sides of the Atlantic suggest moderation in both drink and in the consumption of the heavier meals served in restaurants, and may be a pathway to the ill health found above.

Another potential pathway is through increased stress which, as discussed before, the medical literature has linked to adverse health outcomes. The BHPS lists several self-reported measures of stress through the General Health Questionnaire (GHQ), including difficulties with sleep, making decisions, feeling under strain, ability to overcome difficulties, loss of confidence, and general happiness. As with the health outcomes above, a sample from Wave 8 of the BHPS is utilised where the respondents are reporting 'low stress' (e.g. no problems with sleep, making decisions, not feeling under strain, no problems with ability to overcome difficulties, no loss of confidence and feeling generally happy) and track these workers over the next ten waves of the BHPS to assert whether they report a higher stress level. In addition, as above, this is estimated for the standard Cox model, as well as the PG model without and with frailty for several different samples.

The results for these regressions are found in Table 4. Overall the general results mimic the results for health - namely, that an increase in the percentage of time spent in performance pay increases the hazard to report more stress (across ALL stress measures) or lower happiness. For sleep difficulties the Cox estimates are around 1.003 or 1.004 for all subsamples, including when past sleep problems (before Wave 8) are controlled for. The hazards also increase when frailty is 
controlled for to at least 1.016 (when past health is controlled for) and as high as 1.031 for manual workers. All of the frailty controlled results are statistically significant at least at the ten percent level. This pattern is remarkably consistent for each stress measure or for subjective measures of happiness with most Cox hazards in the 1.003 to 1.009 range and the frailty corrected PG hazards between 1.009 and 1.041, and except for a handful of samples, all are statistically significant. While this is not a proof of a link between performance pay and health, it is suggestive of a pathway where performance pay may impact the health of workers.

\section{Conclusions and Future Work}

Previous research shows that performance related pay generates increased effort and productivity at work. However, it may also generate a series of unintended consequences. Observations by Adam Smith indicate that one such consequence might be on the health of workers, although little has been done to estimate whether his observation has empirical validity. Using multiple waves of the BHPS and duration models, this study finds that increasing the time in which workers' pay comprises at least in part of performance pay generates higher odds of falling into bad health - either measured by subjective health or along one of three physical health dimensions. These results are very robust to variations in variables or estimation procedure. In addition, the estimates serve as a lower bound of the negative effect of performance pay on health since even if endogeneity is not perfectly captured in the regressions there will be a likely positive bias due to healthier workers selecting performance pay jobs.

Furthermore the study investigates potential pathways in which this linkage between performance pay and health might lay. While performance pay is found to increase work time, it 
does not seem to be significantly correlated with activities designed to promote health, although performance pay is correlated with increases in drinking and restaurant meals. A more consistent pattern is found with a series of measures of stress, where increases in the time spent in performance pay increase the hazard of five measures of stress.

Although a very robust relationship between performance-based pay and the duration of good health is unearthed, there are several limitations in the paper. First, we measure performance pay only broadly. The strongest theoretical effects should come through individual-based performance pay, but this information is not available in the BHPS. Similarly, one cannot measure the intensity of individual pay (that is, what proportion of pay is based on performance), meaning that the implicit assumption that any intensity of performance pay generates the same health outcomes is entertained when the effects are likely strongest for those whose pay is mostly determined by performance. Finally, that study cannot control for changing jobs, which can also induce stress. If workers are forced to change jobs that happen to have a performance pay aspect, there may be a stronger correlation between performance pay and ill health because of this job change stress. Yet, there will also be workers who are forced to change jobs that will have no performance pay, and thus, it is not clear how strong this bias might be. However, the effects of such unobserved factors are mitigated by the frailty corrections for omitted variables (Jenkins, 2013).

Performance pay can generate a variety of efficient labour market outcomes. However, the findings here are firmly in the camp of a potential unintended consequence of performance pay and support the insight of Adam Smith. Like other research that finds that performance pay can 
lead to workers, for example, focusing on quantity rather than quantity or overusing physical capital, long term exposure to performance pay is related to worse health, suggesting that firms may face increased health insurance or workers compensation costs (e.g. Freeman and Kleiner, 2005) and the society as a whole may bear the costs of a less productive and less healthy workforce with important repercussions for the health services. Perhaps to mitigate these increases in costs, future research, using more detailed health data, should focus on identifying the pathways that performance pay can affect health. Unfortunately, the BHPS offers information on few and relatively crude approximations of the pathways. It may well be through increased stress, as suggested in the results here, but this should be more explicitly examined with more detailed data. Further research may extend this argument to other forms of payment schemes. For example, stress and other factors that can induce ill health may increase in 'tournaments' where there is a 'winner-take-all' payoff, so that the effects of fierce competition for promotions would be an interesting extension of this research.

Acknowledgements: The authors are thankful for comments from participants of the 2010 ALMR Conference, the 2012 HEALTHatWORK Conference, the 2013 Scottish Economic Society Conference, and seminar participants at the University of Wisconsin-Milwaukee and the Health Economics Research Unit at the University of Aberdeen as well as discussions with John Heywood, Colin Green and Yu Aoki. The authors are also grateful to the anonymous referees of this journal for their very helpful comments.

The financial support of the European Commission is gratefully acknowledged (HEALTHatWORK project - 7th Framework Programme "THEME [HEALTH-2007-4.2-3] Grant agreement no: 200716. 


\section{References}

Artz, Benjamin and John S. Heywood. 2013. "Performance Pay and Workplace Injury: US Survey Evidence,” University of Wisconsin-Milwaukee working paper, Milwaukee, Wisconsin.

Belman, Dale L, Kristen A. Monaco and Taggert J. Brooks. 2005. Sailors of the Concrete Sea: A Portrait of Truck Drivers' Work and Lives, East Lansing Michigan: Michigan State University Press.

Bender, Keith A., Colin P. Green, and John S. Heywood. 2012. "Piece Rates and Workplace Injury: Does Survey Evidence Support Adam Smith?” Journal of Population Economics. 25(2): 569-90.

Blake, C.G., S.D. Saleh, and H.H. Whorms. 1996. "Stress and Satisfaction as a Function of Technology and Supervision Type,” International Journal of Operations \& Production Management, 16(5): 64-73.

Case, Ann and Angus Deaton. 2005. "Broken Down by Work and Sex: How Our Health Declines," in Analyses in the Economics of Aging, ed. by David Wise, Chicago: University of Chicago Press, 185-212.

Cooper, C.L. and J. Marshall. 1976. “Occupational Sources of Stress: A Review of the Literature Relating to Coronary Heart Disease and Mental Ill-Health.” Journal of Occupational Psychology, 49: 11-28.

Cooper, D., W.D. McCausland, and I. Theodossiou. 2008. "Unemployed, Uneducated, and Sick: The Effects of Socio-economic Status on Health Duration in the European Union," Journal of the Royal Statistical Society Series A: Statistics in Society, 171(4): 939-52.

Cornelissen, Thomas, John S. Heywood, and Uwe Jirjahn. 2011. "Performance Pay, Risk Attitudes and Job Satisfaction,” Labour Economics, 18: 229-39.

Cox, D.R. 1972. "Regression Models and Life Tables," Journal of the Royal Statistical Society, Series B 34: 187-220.

Dohmen, Thomas and Armin Falk. 2011. "Performance Pay and Multidimensional Sorting: Productivity, Preferences, and Gender,” American Economic Review 101(2): 556-90.

Fletcher, Jason M., Jody L. Sindelar, and Shintaro Yamaguchi. 2011. “Cumulative Effects of Job Characteristics on Health,” Health Economics 20: 553-70.

Foster, Andrew D. and Mark R. Rosenzweig. 1994. "A Test for Moral Hazard in the Labor Market: Contractual Arrangements, Effort, and Health,” Review of Economics and Statistics 74: 213-27.

Freeman, Richard D. and Morris Kleiner. 2005. "The Last American Shoe Manufactures: Decreasing Productivity and Increasing Profits in a Shift from Piece Rates to Continuous Flow Production,” Industrial Relations 44: 307 - 330.

Grund, Christian and Dirk Sliwka. 2010. "Evidence on Performance Pay and Risk Aversion,” Economics Letters, 102: 8-11.

Heckman, J. and G. Borjas. 1990. "Does Unemployment Cause Future Unemployment? Definitions, Questions and Answers from a Continuous Time Model of Heterogeneity and State Dependence,” Economica, 47: 247-83.

Jenkins, S. 1995. “Easy Estimation Methods for Discrete-Time Duration Models,” Oxford Bulletin of Economics and Statistics 57(1): 129-138.

Jenkins S. (2004) "Discrete time (grouped data) proportional hazards models”, (Available from http://fmwww.bc.edu/repec/bocode/p/pgmhaz8.html, (last accessed 05/3/2013)). 
Jenkins, S. (2005) Discrete time (grouped data) proportional hazard models. Institute for Social and Economic Research, University of Essex, Colchester. http://fmwww.bc.edu/RePEc/bocode/h/hshaz.hlp (last accessed 05/3/2013)).

Jenkins, S. (2013) Survival Analysis, manuscript, https://www.iser.essex.ac.uk/files/teaching/stephenj/ec968/pdfs/ec968lnotesv6.pdf, (last accessed 12/3/2013).

Khwaja, Ahmed, Frank Sloan and Martin Salm. 2006. "Evidence on Preferences and Subjective Beliefs of Risk Takers: The Case of Smokers,” International Journal of Industrial Organization 24: 667-82

Kowert, P.A. and M.G. Hermann. 1997. "Who Takes Risks? Daring and Caution in Foreign Policy Making,” Journal of Conflict Resolution 41: 611-37.

Lancaster, T. 1979. "Econometric Methods for the Duration of Unemployment," Econometrica, 47(4): 939-956.

Lazear, Edward P. 2000. "Performance Pay and Productivity,” American Economic Review 90: $1346-61$.

Lia, Shu and Chang-Jiang Liu. 2008. "Individual Differences in a Switch from Risk-Averse Preferences for Gains to Risk-Seeking Preferences for Losses: Can Personality Variables Predict the Risk Preferences?” Journal of Risk Research 11: 673-86.

MacDonald, Glenn and Leslie M. Marx. 2001. “Adverse Specialization,” Journal of Political Economy 109: 864 - 99.

Meyer, B.D. 1990. “Unemployment Insurance and Unemployment Spells,” Econometrica 58(4): 757-782.

Monaco, Kristen and Emily Williams. 2000. "Assessing the Determinants of Safety in the Trucking Industry,” Journal of Transportation and Statistics 3: 69 - 80.

Mullahy, John and Stephanie A. Robert. 2010. "No Time to Lose: Time Constraints and Physical Activity in the Production of Health," Review of the Economics of the Household 8: 40932.

Nicholson, N., E. Soane, M. Fenton-O’Creevy and P. Willman. 2005. "Personality and DomainSpecific Risk Taking,” Journal of Risk Research 8: 157-76.

Prentice, R. and L. Gloeckler. 1978. "Regression Analysis of Grouped Survival Data with Application to Breast Cancer Data," Biometrics 34: 57-67.

Rodriquez, Daniel A., Filipe Targa and Michael Belzer. 2006. "Pay Incentives and Truck Driver Safety: a Case Study,” Industrial and Labor Relations Review 59: 205 - 225.

Saha, Asim, Takiar Tamnath, Ramendra Chaudhuri and Habibullah Saiyed. 2004. "An AccidentRisk Assessment Study of Temporary Piece Rated Workers,” Industrial Health 42: 240 45.

Smith, Adam, 1776. An Inquiry into the Nature and Causes of the Wealth of Nations as reprinted in 1909, edited by C. J. Bullock, P.F. Collier \& Son: New York.

Sundstroem-Frisk, Carin. 1984. "Behavioral Control through Piece-rate Wages," Journal of Occupational Accidents 6: 49-59.

Toupin, Dominic, Luc LeBel, Denise Dubeau, Daniel Imbeau and Luc Bouthiller. 2007. "Measuring the Productivity and Physical Workload of Brushcutters within the Context of a Production-Based Pay System,” Forest Policy and Economics 9: 1046 - 55.

Williamson, Ann, Philip Bohle, Michael Quinlan, and David Kennedy. 2009. "Short Trips and Long Days: Safety and Health in Short-Haul Trucking,” Industrial and Labor Relations 
Review 62: 415-29.

Viscusi, W. Kip. 2001. "Cigarette Smokers as Job Risk Takers," The Review of Economics and Statistics 83: 269-80. 
Table 1. Selected Results for Hazard Ratios for Overall Subjective Health: Odds Ratio on Percentage of Time Spent in Performance Pay

\begin{tabular}{lccc} 
& & \multicolumn{2}{c}{ Prentice-Gloeckler } \\
Sample & Cox & w/o Frailty & w/ Frailty \\
\hline Overall & $1.004^{* * *}$ & $1.005^{* * *}$ & $1.013^{* * *}$ \\
& $(3.42)$ & $(4.01)$ & $(3.01)$ \\
Overall with Past & $1.004^{* * *}$ & $1.004^{* * *}$ & $1.009^{* *}$ \\
$\quad$ health controlled & $(2.93)$ & $(3.37)$ & $(2.57)$ \\
Female & $1.004^{* *}$ & $1.004^{* *}$ & 1.009 \\
& $(1.97)$ & $(2.46)$ & $(1.57)$ \\
Male & $1.004^{* * *}$ & $1.005^{* * *}$ & $1.017^{* *}$ \\
& $(2.73)$ & $(3.31)$ & $(2.45)$ \\
Income<=median & $1.005^{* * *}$ & $1.005^{* * *}$ & $1.017^{* *}$ \\
& $(2.91)$ & $(2.93)$ & $(2.37)$ \\
Income>median & $1.004^{* * *}$ & $1.005^{* * *}$ & $1.014^{* *}$ \\
& $(2.39)$ & $(2.78)$ & $(2.38)$ \\
Manual occupation & $1.007^{* * *}$ & $1.008^{* * *}$ & $1.025^{* * *}$ \\
& $(2.79)$ & $(3.31)$ & $(2.60)$ \\
Nonmanual occupation & $1.003^{* *}$ & $1.004^{* * *}$ & $1.010^{* *}$ \\
& $(2.36)$ & $(2.78)$ & $(2.00)$ \\
\hline
\end{tabular}

Notes: z-statistics under odds ratios. All regressions also include a constant and indicators for gender, noncompletion of secondary education (excluded), completion of secondary education, completion of postsecondary education, age less than 26 (excluded), age between 26-35, age between 36-45, age between46-55, age above 55, married, currently smoking, labour income quartile, the log of hours worked, broad industry and occupation and region where the P-G regressions also include log of time. Numbers under odds ratios are asymptotic z-statistics. *, $* *$, and $* * *$ indicate statistical significance at the 10, 5 and 1 percent level. The sample is those people who were working in wage and salary jobs for the entire time we observe them and who start out with excellent or very good subjective health in wave eight. For the overall sample, there are 2,410 observations where $51 \%$ are censored. 
Table 2. Hazard ratios for the Percentage of Time Spent in Performance Pay by Objective Health Measure

\begin{tabular}{|c|c|c|c|}
\hline \multirow{2}{*}{ Sample } & \multirow[b]{2}{*}{ Cox } & \multicolumn{2}{|c|}{ Prentice-Gloeckler } \\
\hline & & w/o Frailty & w/ Frailty \\
\hline \multicolumn{4}{|l|}{ Heart Health $(n=2,694)$} \\
\hline \multirow[t]{2}{*}{ Full } & $1.008 * * *$ & $1.008 * * *$ & $1.026 * * *$ \\
\hline & $(4.24)$ & $(4.49)$ & $(5.02)$ \\
\hline \multirow{2}{*}{$\begin{array}{l}\text { Overall with Past health } \\
\text { controlled }\end{array}$} & $1.006 * * *$ & $1.007 * * *$ & $1.009 * * *$ \\
\hline & $(2.85)$ & $(2.97)$ & $(2.85)$ \\
\hline \multirow[t]{2}{*}{ Female } & $1.008 * * *$ & $1.008 * * *$ & $1.039 * * *$ \\
\hline & $(3.12)$ & $(3.31)$ & $(3.47)$ \\
\hline \multirow[t]{2}{*}{ Male } & $1.008^{* * *}$ & $1.008 * * *$ & $1.018 * * *$ \\
\hline & $(3.08)$ & $(3.26)$ & $(3.07)$ \\
\hline \multirow[t]{2}{*}{ Income $<=$ median } & $1.009 * * *$ & $1.009 * * *$ & $1.022 * * *$ \\
\hline & (3.29) & (3.49) & $(2.86)$ \\
\hline \multirow[t]{2}{*}{ Income $>$ median } & $1.006^{* *}$ & $1.006 * *$ & $1.029 * * *$ \\
\hline & $(2.27)$ & $(2.36)$ & $(3.60)$ \\
\hline \multirow[t]{2}{*}{ Manual } & 1.005 & 1.006 & 1.010 \\
\hline & (1.39) & $(1.48)$ & $(1.43)$ \\
\hline \multirow[t]{2}{*}{ Nonmanual } & $1.008 * * *$ & $1.009 * * *$ & $1.039 * * *$ \\
\hline & $(3.97)$ & $(4.20)$ & $(4.40)$ \\
\hline \multicolumn{4}{|l|}{ Stomach Health $(n=2,675)$} \\
\hline \multirow[t]{2}{*}{ Full } & $1.008^{* * *}$ & $1.009 * * *$ & $1.021 * *$ \\
\hline & $(4.14)$ & $(4.47)$ & $(2.36)$ \\
\hline \multirow{2}{*}{$\begin{array}{l}\text { Overall with Past health } \\
\text { controlled }\end{array}$} & $1.006 * *$ & $1.007 * * *$ & $1.008 * *$ \\
\hline & $(2.41)$ & $(2.66)$ & $(2.75)$ \\
\hline \multirow[t]{2}{*}{ Female } & $1.006^{*}$ & $1.006 * *$ & 0.999 \\
\hline & $(1.91)$ & $(2.14)$ & $(-0.07)$ \\
\hline \multirow[t]{2}{*}{ Male } & $1.010 * * *$ & $1.011 * * *$ & $1.030 * *$ \\
\hline & $(3.83)$ & $(4.06)$ & $(2.36)$ \\
\hline \multirow[t]{2}{*}{ Income $<=$ median } & $1.006 * *$ & $1.006^{*}$ & 1.007 \\
\hline & $(2.07)$ & (1.93) & $(0.39)$ \\
\hline \multirow[t]{2}{*}{ Income $>$ median } & $1.009 * * *$ & $1.010 * * *$ & $1.027 * * *$ \\
\hline & $(3.56)$ & $(3.97)$ & $(2.65)$ \\
\hline \multirow[t]{2}{*}{ Manual } & $1.016^{* * *}$ & $1.017 * * *$ & $1.042^{* *}$ \\
\hline & $(4.44)$ & $(4.75)$ & $(2.05)$ \\
\hline \multirow[t]{2}{*}{ Nonmanual } & $1.005^{* *}$ & $1.006 * *$ & 1.019 \\
\hline & $(2.14)$ & $(2.37)$ & $(1.34)$ \\
\hline Anxiety/Depression $(n=2,70$ & & & \\
\hline Full & $1.007 * * *$ & $1.007 * * *$ & $1.020 * *$ \\
\hline & $(3.52)$ & (3.79) & $(2.53)$ \\
\hline Overall with Past health & $1.009 * * *$ & $1.010^{* * *}$ & $1.011^{* * *}$ \\
\hline controlled & $(3.58)$ & $(3.73)$ & $(3.49)$ \\
\hline Female & $1.010 * * *$ & $1.011 * * *$ & $1.038 * *$ \\
\hline & $(4.60)$ & $(4.94)$ & $(2.57)$ \\
\hline Male & 0.999 & 0.999 & $1.049 * *$ \\
\hline & $(-0.25)$ & $(-0.24)$ & $(2.07)$ \\
\hline Income $<=$ median & $1.008 * * *$ & $1.007 * * *$ & 1.021 \\
\hline & $(3.07)$ & $(2.78)$ & $(1.54)$ \\
\hline Income >median & $1.006 * *$ & $1.007 * *$ & $1.021^{* *}$ \\
\hline & $(2.17)$ & $(2.37)$ & $(2.05)$ \\
\hline Manual & $1.013 * * *$ & $1.014 * * *$ & 1.187 \\
\hline & $(3.07)$ & $(3.26)$ & $(1.57)$ \\
\hline Nonmanual & $1.006 * *$ & $1.006^{* * *}$ & $1.017 * *$ \\
\hline & $(2.59)$ & $(2.91)$ & $(2.21)$ \\
\hline
\end{tabular}

Notes: Same covariates as in Table 1. Numbers under hazard ratios are asymptotic z-statistics. $*$, ** and *** indicate statistical significance at the 10, 5 and 1 percent level, respectively. Sample sizes are given above. 
Table 3. Selected Ordered Probit Regression Results for Coefficient on Percentage of Time Spent in Performance Pay

\begin{tabular}{llc} 
Leisure Activity & Sample & Coefficient \\
\hline Sports & Healthy workers & -0.019 \\
& & $-0.27)$ \\
& All workers & -0.017 \\
Evening classes (incl keep fit) & Healthy workers & $(-0.41)$ \\
& & -0.043 \\
& All workers & $-0.55)$ \\
& & 0.009 \\
Drink & Healthy workers & $(0.18)$ \\
& & $0.148^{* *}$ \\
& All workers & $(2.22)$ \\
Eat Out & & $0.134^{* * *}$ \\
& Healthy workers & $(3.34)$ \\
& & $0.123^{*}$ \\
& All workers & $(1.90)$ \\
& & $0.130^{* * *}$ \\
\hline
\end{tabular}

Notes: Regressions based on data on wage and salary workers from Wave 8 of the BHPS. Other covariates include: gender, education, age, age squared, marital status, indicator for currently smoking, labour income, occupation and region. 
Table 4. GHQ: Stress Results. Hazard Ratio on Percentage of Time in Performance Pay by Duration Model and Sample

\begin{tabular}{|c|c|c|c|}
\hline \multirow[b]{2}{*}{ Sample } & \multirow[b]{2}{*}{ Cox Regression } & \multicolumn{2}{|c|}{ Prentice-Gloeckler } \\
\hline & & w/o Frailty & with Frailty \\
\hline \multicolumn{4}{|l|}{ Sleep $(n=2,703)$} \\
\hline \multirow[t]{2}{*}{ Full } & $1.003^{* * *}$ & $1.004^{* * *}$ & $1.020^{* * *}$ \\
\hline & (3.30) & $(4.17)$ & (3.22) \\
\hline \multirow{2}{*}{$\begin{array}{l}\text { Overall with Past health } \\
\text { controlled }\end{array}$} & $1.003^{* * *}$ & $1.004 * * *$ & $1.016^{* * *}$ \\
\hline & $(3.32)$ & $(4.27)$ & $(2.95)$ \\
\hline \multirow[t]{2}{*}{ Income $<$ median } & $1.003 *$ & $1.004^{* *}$ & $1.017 *$ \\
\hline & $(1.87)$ & $(2.34)$ & $(1.80)$ \\
\hline \multirow[t]{2}{*}{ Income>median } & $1.004 * * *$ & $1.005^{* * *}$ & $1.022^{* * *}$ \\
\hline & (2.99) & (3.79) & $(2.71)$ \\
\hline \multirow[t]{2}{*}{ Female } & $1.004 * *$ & $1.005^{* * *}$ & $1.017 * *$ \\
\hline & $(2.48)$ & $(3.20)$ & $(2.28)$ \\
\hline \multirow[t]{2}{*}{ Male } & $1.003 *$ & $1.003^{* *}$ & $1.023^{* *}$ \\
\hline & $(1.85)$ & $(2.34)$ & $(2.02)$ \\
\hline \multirow[t]{2}{*}{ Manual } & 1.003 & 1.004 & $1.031^{*}$ \\
\hline & (1.47) & $(1.60)$ & $(1.83)$ \\
\hline \multirow[t]{2}{*}{ Nonmanual } & $1.003 * * *$ & $1.004^{* * *}$ & $1.016^{* *}$ \\
\hline & $(2.70)$ & $(3.57)$ & $(2.43)$ \\
\hline \multicolumn{4}{|l|}{ Decision Making $(n=2,858)$} \\
\hline \multirow[t]{2}{*}{ Full } & $1.004^{* * *}$ & $1.005^{* * *}$ & $1.024 * * *$ \\
\hline & $(3.12)$ & $(3.54)$ & (3.18) \\
\hline \multirow{2}{*}{$\begin{array}{l}\text { Overall with Past health } \\
\text { controlled }\end{array}$} & $1.004^{* * *}$ & $1.005 * * *$ & $1.019 * * *$ \\
\hline & (3.17) & (3.55) & $(2.85)$ \\
\hline \multirow[t]{2}{*}{ Income $<$ median } & 1.003 & $1.004 *$ & 1.019 \\
\hline & (1.39) & $(1.65)$ & $(1.62)$ \\
\hline \multirow[t]{2}{*}{ Income>median } & $1.005^{* * *}$ & $1.006^{* * *}$ & $1.036^{* * *}$ \\
\hline & $(2.88)$ & $(3.45)$ & $(3.38)$ \\
\hline \multirow[t]{2}{*}{ Female } & $1.004^{* *}$ & $1.004^{* *}$ & $1.032^{* *}$ \\
\hline & $(2.04)$ & $(2.36)$ & $(2.52)$ \\
\hline \multirow[t]{2}{*}{ Male } & $1.005^{* *}$ & $1.005^{* * *}$ & $1.022^{* *}$ \\
\hline & (2.36) & $(2.66)$ & $(2.02)$ \\
\hline \multirow[t]{2}{*}{ Manual } & $1.008^{* * *}$ & $1.009 * * *$ & $1.027 * *$ \\
\hline & $(2.76)$ & $(3.06)$ & (1.98) \\
\hline \multirow[t]{2}{*}{ Nonmanual } & $1.004^{* *}$ & $1.004^{* * *}$ & $1.026^{* *}$ \\
\hline & $(2.44)$ & $(2.82)$ & $(2.54)$ \\
\hline Under Strain $(n=2,405)$ & & & \\
\hline Full & $1.005^{* * *}$ & $1.007^{* * *}$ & $1.035^{* * *}$ \\
\hline & $(5.52)^{-1}$ & $(7.07)$ & $(4.68)^{* * *}$ \\
\hline $\begin{array}{l}\text { Overall with Past health } \\
\text { controlled }\end{array}$ & $1.005^{* * *}$ & $1.006 * * *$ & $1.029 * * *$ \\
\hline $\begin{array}{l}\text { controlled } \\
\text { Income }<\text { median }\end{array}$ & $(5.17)^{(4 * *}$ & $(6.78)$ & $(4.22)$ \\
\hline Income <median & $\begin{array}{l}1.005^{* * *} \\
(3.23)\end{array}$ & $\begin{array}{l}1.007^{* * *} \\
(4.48)\end{array}$ & $\begin{array}{l}1.037 * * * \\
(2.87)\end{array}$ \\
\hline Income>median & $1.005 * * *$ & $1.006^{* * *}$ & $1.037^{* * *}$ \\
\hline & $(4.11)$ & (5.59) & (3.93) \\
\hline Female & $1.006^{* * *}$ & $1.008 * * *$ & $1.034^{* * *}$ \\
\hline & $(4.27)$ & $(5.50)$ & $(3.25)$ \\
\hline Male & $1.004 * * *$ & $1.005^{* * *}$ & $1.036^{* * *}$ \\
\hline & $(3.00)$ & $(3.81)$ & (3.23) \\
\hline Manual & $1.007 * * *$ & $1.008^{* * *}$ & $1.037 * * *$ \\
\hline & (3.33) & (3.85) & $(2.85)$ \\
\hline Nonmanual & $1.005 * * *$ & $1.006 * * *$ & $1.041^{* * *}$ \\
\hline & $(4.26)$ & $(5.64)$ & (3.89) \\
\hline
\end{tabular}




\begin{tabular}{|c|c|c|c|}
\hline \multicolumn{4}{|l|}{ Overcome Difficulties ( $n=2,791)$} \\
\hline Full & $\begin{array}{l}1.005^{* * *} \\
(4.02)\end{array}$ & $\begin{array}{l}1.006^{* * *} \\
(4.80)\end{array}$ & $\begin{array}{l}1.022^{* * *} \\
(3.50)\end{array}$ \\
\hline $\begin{array}{l}\text { Overall with Past health } \\
\text { controlled }\end{array}$ & $\begin{array}{l}1.004 * * * \\
(3.74)\end{array}$ & $\begin{array}{l}1.005^{* * *} \\
(4.32)\end{array}$ & $\begin{array}{l}1.018^{* * *} \\
(3.42)\end{array}$ \\
\hline Income $<$ median & $\begin{array}{l}1.005^{* * *} \\
(2.77)\end{array}$ & $\begin{array}{l}1.005^{* * *} \\
(3.02)\end{array}$ & $\begin{array}{l}1.026^{* *} \\
(2.49)\end{array}$ \\
\hline Income $>$ median & $\begin{array}{l}1.004 * * * \\
(2.79)\end{array}$ & $\begin{array}{l}1.006^{* * *} \\
(3.75)\end{array}$ & $\begin{array}{l}1.009^{* * *} \\
(4.69)\end{array}$ \\
\hline Female & $\begin{array}{l}1.005^{* * *} \\
(3.11)\end{array}$ & $\begin{array}{l}1.006^{* * *} \\
(3.77)\end{array}$ & $\begin{array}{l}1.024^{* * *} \\
(2.69)\end{array}$ \\
\hline Male & $\begin{array}{l}1.004 * * \\
(2.31)\end{array}$ & $\begin{array}{l}1.005^{* * *} \\
(2.79)\end{array}$ & $\begin{array}{l}1.019 * \\
(1.94)\end{array}$ \\
\hline Manual & $\begin{array}{l}1.009 * * * \\
(3.71)\end{array}$ & $\begin{array}{l}1.010^{* * *} \\
(4.19)\end{array}$ & $\begin{array}{l}1.041^{* * *} \\
(2.99)\end{array}$ \\
\hline Nonmanual & $\begin{array}{l}1.003^{* *} \\
(2.53)\end{array}$ & $\begin{array}{l}1.004^{* * *} \\
(3.21)\end{array}$ & $\begin{array}{l}1.013^{*} \\
(1.76)\end{array}$ \\
\hline Lose Confidence $(n=2,787)$ & & & \\
\hline Full & $\begin{array}{l}1.003^{* *} \\
(2.44)\end{array}$ & $\begin{array}{l}1.004^{* * *} \\
(3.01)\end{array}$ & $\begin{array}{l}1.023^{* *} \\
(2.14)\end{array}$ \\
\hline $\begin{array}{l}\text { Overall with Past health } \\
\text { controlled }\end{array}$ & $\begin{array}{l}1.003^{* *} \\
(2.59)\end{array}$ & $\begin{array}{l}1.004^{* * *} \\
(3.22)\end{array}$ & $\begin{array}{l}1.010^{* *} \\
(2.02)\end{array}$ \\
\hline Income $<$ median & $\begin{array}{l}1.005^{* * *} \\
(2.91)\end{array}$ & $\begin{array}{l}1.005^{* * *} \\
(2.85)\end{array}$ & $\begin{array}{l}1.021^{* *} \\
(2.21)\end{array}$ \\
\hline Income $>$ median & $\begin{array}{l}1.001 \\
(0.74)\end{array}$ & $\begin{array}{c}1.002 \\
(1.39)\end{array}$ & $\begin{array}{c}1.010 \\
(1.40)\end{array}$ \\
\hline Female & $\begin{array}{l}1.004^{* *} \\
(2.37)\end{array}$ & $\begin{array}{l}1.005^{* * *} \\
(2.96)\end{array}$ & $\begin{array}{l}1.015^{*} \\
(1.93)\end{array}$ \\
\hline Male & $\begin{array}{l}1.002 \\
(0.98)\end{array}$ & $\begin{array}{l}1.002 \\
(1.25)\end{array}$ & $\begin{array}{c}1.014 \\
(1.35)\end{array}$ \\
\hline Manual & $\begin{array}{l}1.006^{* *} \\
(2.05)\end{array}$ & $\begin{array}{l}1.007^{* *} \\
(2.33)\end{array}$ & $\begin{array}{l}1.041^{* *} \\
(2.56)\end{array}$ \\
\hline Nonmanual & $\begin{array}{l}1.002^{*} \\
(1.75)\end{array}$ & $\begin{array}{l}1.003^{* *} \\
(2.31)\end{array}$ & $\begin{array}{l}1.004 \\
(0.69)\end{array}$ \\
\hline Happiness $(n=2,769)$ & & & \\
\hline Full & $\begin{array}{l}1.004^{* * *} \\
(3.16)\end{array}$ & $\begin{array}{l}1.004^{* * *} \\
(3.91)\end{array}$ & $\begin{array}{l}1.016^{* * *} \\
(3.15)\end{array}$ \\
\hline $\begin{array}{l}\text { Overall with Past health } \\
\text { controlled }\end{array}$ & $\begin{array}{l}1.004^{* * *} \\
(3.16)\end{array}$ & $\begin{array}{l}1.004^{* * *} \\
(3.67)\end{array}$ & $\begin{array}{l}1.009^{* *} \\
(2.18)\end{array}$ \\
\hline Income $<$ median & $\begin{array}{l}1.003 \\
(1.64)\end{array}$ & $\begin{array}{l}1.003^{* *} \\
(1.96)\end{array}$ & $\begin{array}{l}1.016^{* *} \\
(2.03)\end{array}$ \\
\hline Income>median & $\begin{array}{l}1.004 * * \\
(2.42)\end{array}$ & $\begin{array}{l}1.005^{* * *} \\
(3.35)\end{array}$ & $\begin{array}{l}1.018^{* * *} \\
(2.73)\end{array}$ \\
\hline Female & $\begin{array}{l}1.004 * * * \\
(2.72)\end{array}$ & $\begin{array}{l}1.005^{* * *} \\
(3.43)\end{array}$ & $\begin{array}{l}1.019^{* *} \\
(2.56)\end{array}$ \\
\hline Male & $\begin{array}{l}1.003 * \\
(1.67)\end{array}$ & $\begin{array}{l}1.003^{* *} \\
(2.07)\end{array}$ & $\begin{array}{l}1.013^{*} \\
(1.76)\end{array}$ \\
\hline Manual & $\begin{array}{l}1.004^{*} \\
(1.73)\end{array}$ & $\begin{array}{l}1.005^{* *} \\
(1.96)\end{array}$ & $\begin{array}{l}1.016^{*} \\
(1.82)\end{array}$ \\
\hline Nonmanual & $\begin{array}{l}1.003^{* *} \\
(2.47)\end{array}$ & $\begin{array}{l}1.004^{* * *} \\
(3.20)\end{array}$ & $\begin{array}{l}1.015^{* *} \\
(2.36)\end{array}$ \\
\hline
\end{tabular}

Notes: Duration model starts with respondents in Wave 8 saying that they have GHQ difficulty 'not at all' or 'no more than usual' or that happiness is 'much more than usual' or the 'same as usual'. Thus failure happens when the respondent reports difficulty 'rather' or 'much' more than usual. Frailty controls for log duration (last three time 
periods combined). Regressions based on data on wage and salary workers from Wave 8 of the BHPS. Other covariates include those in Table 3. Sample sizes given in table. 
Figure 1. Survival Plots for Subjective Health

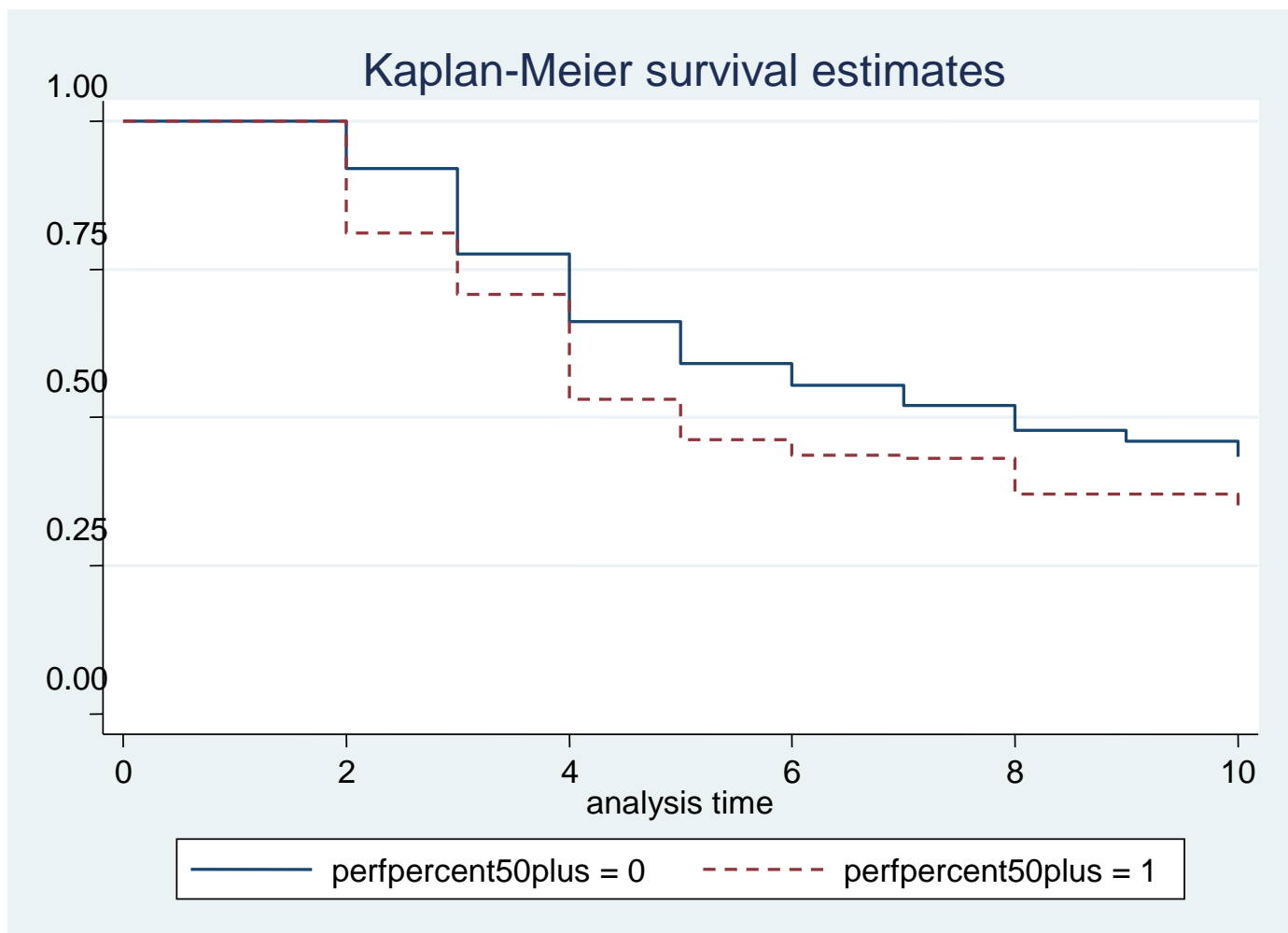

Figure 2. Survival Plots for Subjective Health, Controlling for Earned Income

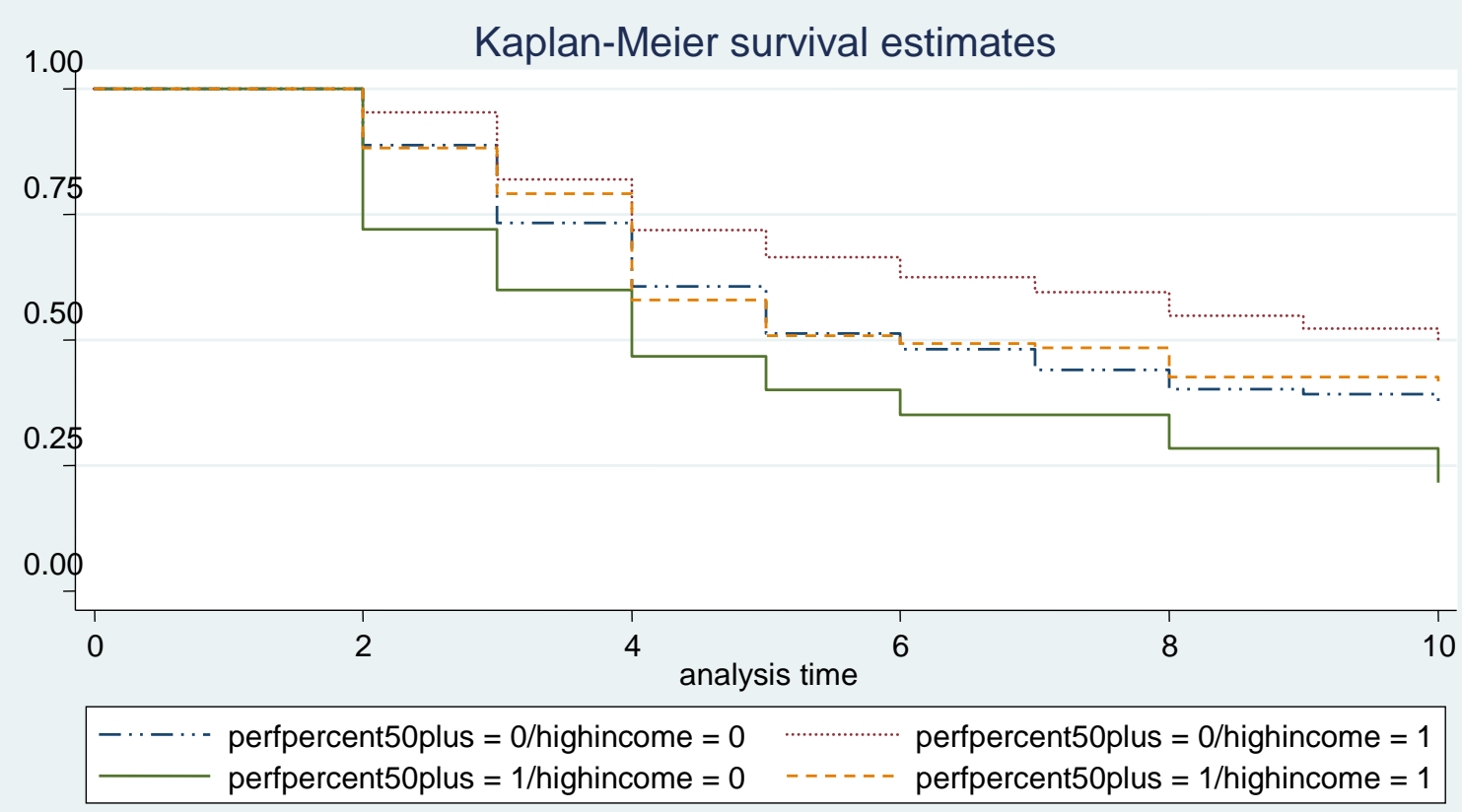


Figure 3. Survival Plots for the Three Objective Measures of Health $\underline{\text { Heart Problems }}$

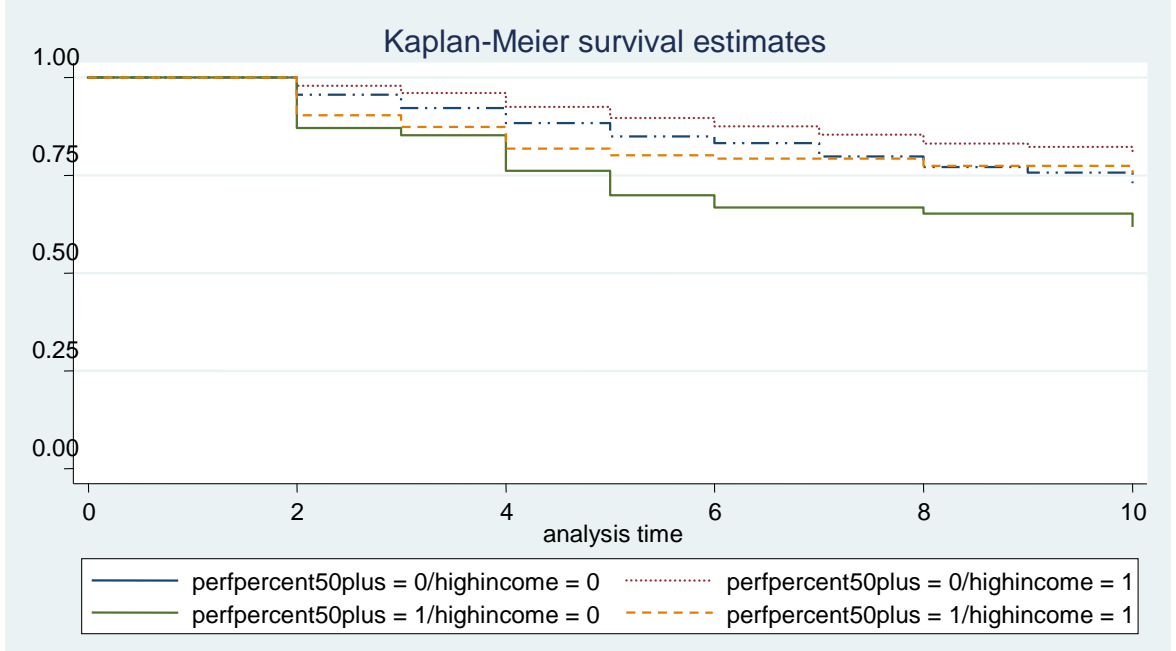

\section{$\underline{\text { Stomach Problems }}$}

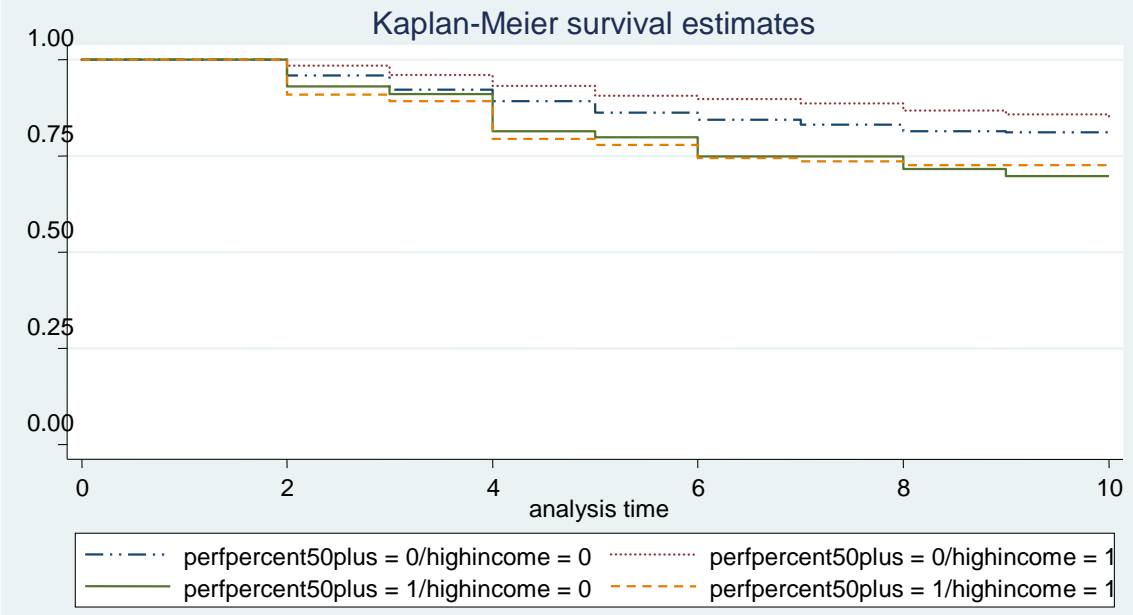

\section{$\underline{\text { Anxiety/Depression }}$}

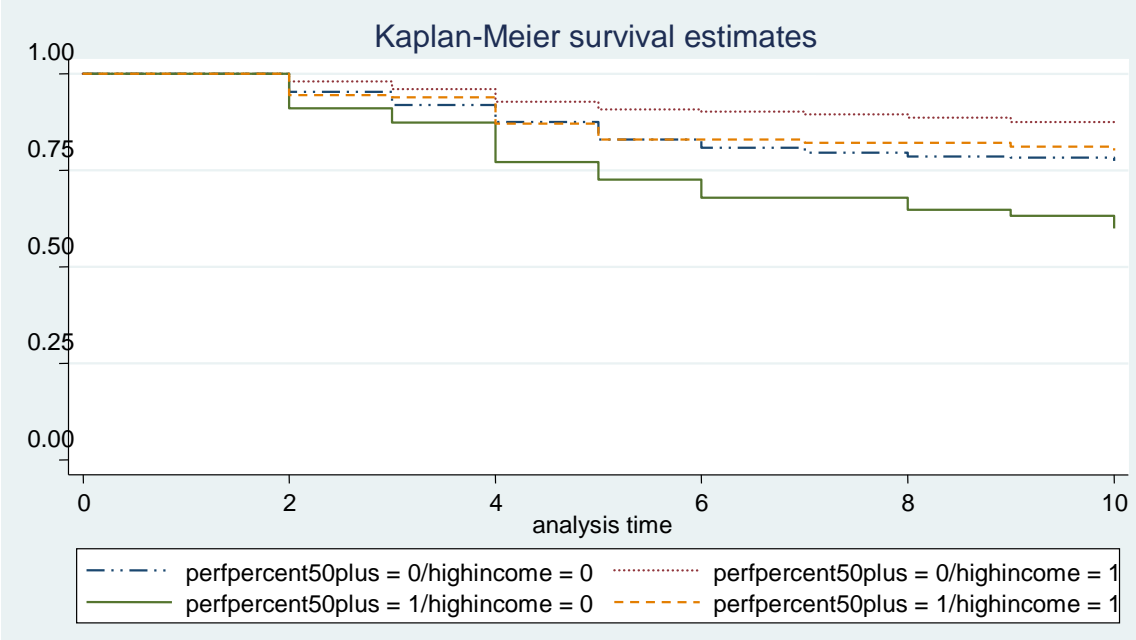


Appendix Table A1: Full Results for Subjective Health for Full Sample: Cox, P-G with and without Frailty: Odds Ratios

Prentice-Gloeckler

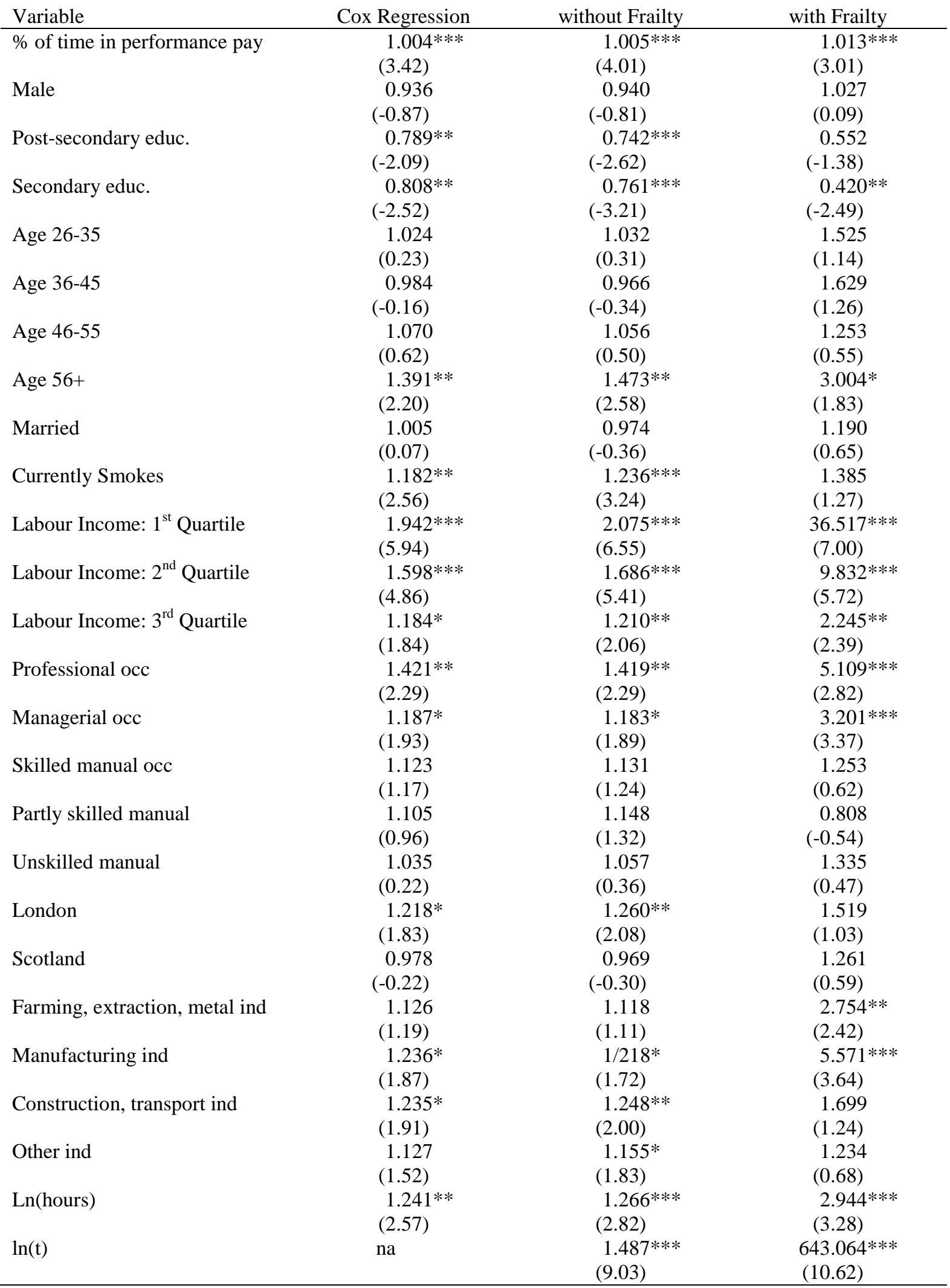


Notes: z-statistics under odds ratios. Regressions also include a constant term. The excluded variables are: did not complete secondary education, age under 26 years, income in $4^{\text {th }}$ quartile, skilled nonmanual occupation, regions of England, Wales and Northern Ireland that are not in greater London or in Scotland, and services and banking industry. ${ }^{*}, * *$, and $* * *$ indicate statistical significance at the 10,5 , and 1 percent level, respectively. 